\title{
Uma perspectiva afro-centrada para produção de
}

\section{narrativas}

\section{Alguns elementos pedagógicos para colocar a experiência de} sujeitos negros no centro do processo de protagonismo com tecnologias

\section{An Afro-centered perspective for narrative production \\ Some pedagogical elements to place the experience of black subjects at the center of the process of protagonism with technologies}

\section{Luiz Carlos Pinto da Costa Júnior}

Professor do curso de Jornalismo e coordenador do Mestrado em Indústrias Criativas da UNICAP. Universidade Católica de Pernambuco, Departamento de Jornalismo, Recife (PE), Brasil.

Introdução

Movimentos sociais, grupos e coletivos de cultura, com experiências de aprendizado baseadas em epistemologias da educação e cultura popular, têm demonstrado que suas práticas culturais, modos de ensinar e construir conhecimentos transbordam as lógicas racional e escolar. Essa percepção, válida também para o campo das apropriações e subversões de tecnologias digitais e em rede, tem permitido observar como tais experiências são soluções localizadas que atendem a demandas gerais, e são caminhos desenvolvidos por sujeitos coletivos formados por uma territorialidade (TEIXEIRA \& PINTO, 2019). Tais 
experiências de aprendizado rompem com uma monoepistemologia exclusivista e reducionista da racionalidade técnico-científica que procura soluções universais às limitações tecnológicas de produção e fruição de informação, cultura e conhecimento.

Alguns termos têm sido usados para se referir a essas práticas de criar, recriar e trocar conhecimentos de forma colaborativa e participativa (WENGER, 2015). Comunidades Educativas, Comunidades Aprendentes, Comunidades Interpretativas, Comunidades de Prática, Redes de Conhecimento, Círculos de Cultura, Coletivos de Cultura são algumas das denominações para formas de organização que podem acontecer local, regional ou mesmo internacionalmente, ou ainda em redes telemáticas, usando TICs, na busca pelo aprendizado em conjunto.

A disposição por tais formas de organização e percurso faz emergirem outras racionalidades, outras afetividades, modos de pensar não dicotomizados, transdisciplinares, indisciplinares e insubmissos. Estão, portanto, em evidente oposição às soluções universalistas que caracterizam a epistemologia moderna, na qual a experiência (empeiria) é considerada em posição inferior à arte (techné) e à ciência (LAROSSA, 2014). Um conjunto amplo de processos de aprendizagem tem mostrado formas de construir conhecimentos que incorporam as dimensões afetivas e espirituais à razão, para construir caminhos metodológicos em oposição ao caminho da pura racionalidade técnica instrumental (TAVARES \& MESQUITA, 2019).

Ao considerarem-se modos de aprendizagem que contemplam as múltiplas dimensões (espiritual, corporal, intelectual, moral, ética etc.) do ser, é necessário atentar às culturas dos coletivos para os quais lançamos nosso olhar. Eles estão localizados no que muitas vezes é chamado de sociedades ou comunidades tradicionais e vivenciam experiências de construção de conhecimentos e realidades de forma coletiva, processual e vivem dentro e nas margens do sistema hegemônico capitalista ocidental.

Este texto sugere elementos pedagógicos que permitem colocar no centro do protagonismo com tecnologias da informação e comunicação a experiência de comunidades afrodescendentes na produção de narrativas em redes telemáticas. Esse objetivo é conduzido tendo dois pressupostos: primeiro, que há uma relação intrínseca e forte entre o ser que conhece e o conhecimento que ele constrói; segundo, que esse conhecimento é coletivo e se incorpora em espaços comuns, onde os sujeitos se encontram e formam comunidade. 
Desenvolver elementos metodológicos de aprendizagem com tecnologias contemporâneas, com as quais se possa produzir e intensificar a circulação de narrativas periféricas, a partir desses elementos, implica considerar algumas consequências. Por um lado, a experiência cotidiana de corpos negros sob as atualizações contemporâneas de negação da fala (RANCIÉRE, 1996) evoca dor, decepção e raiva. Isso implica a necessidade de considerar como os aprendizados com dispositivos tecnológicos, linguagens midiáticas, lógicas algorítmicas e dinâmicas de rede são acionados também no cotidiano para dar conta dos impedimentos específicos da população preta na produção simbólica em rede.

Assim, é importante observar como o cotidiano é o lugar das micro-resistências (CERTEAU, 1994), das insurgências pequenas e quase imperceptíveis; como o uso cotidiano é um recurso importante para desmistificar os aparatos tecnológicos (ao se incorporar ao uso diário o manuseio dessas tecnologias) e também como o cotidiano é a temporalidade em que se vivencia a conexão com a espiritualidade afroindígena brasileira. Com isso, procuro considerar como o cotidiano desempenha um papel importante na construção de um saber-fazer com tecnologias da informação e comunicação que pode ser aproximado da mesma vivência diária dedicada à convivência com os Orixás de matriz Nagô.

Por outro lado, cabe ressaltar e realçar o papel que a própria prática narrativa opera nos processos de aprendizagem com tecnologias da informação e comunicação. "Nas e pelas narrativas, o sujeito executa um trabalho de configuração e interpretação - de dar forma e sentido - da experiência vivida" (DELORYMOMBERGER, 2016, p. 141). Tanto as narrativas de si (individuais e coletivas) quanto as narrativas a partir de mitos fornecem inteligibilidade integrativa às experiências vividas (DELORY- MOMBERGER, 2016).

Como alerta o professor Sílvio Gallo (2012), a concepção platônica do aprender como recognição é a matriz do pensamento educacional e pedagógico. Em termos contemporâneos, a noção de ensinoaprendizagem, implantada pela Psicologia Educacional nos processos educativos, conecta essas duas dimensões (o ensinar e o aprender) de maneira indissolúvel: só se aprende aquilo que é ensinado; não se pode aprender sem que alguém ensine. "O outro lado desta afirmação, fundamental para a Pedagogia, é que se só se aprende aquilo que é ensinado, pode-se controlar o que, como, quanto alguém aprende" (GALLO, 2012, p. 2). Como o autor observa, este controle sobre o aprendizado, por meio do ensino, leva a uma homogeneização, cujo objetivo é que todos aprendam as mesmas coisas, da mesma maneira. 
O aprendizado pela experiência de Larossa (2014) dialoga com a "quase-teoria do aprender" de Deleuze $^{1}$, referências que alimentam a busca dos elementos pedagógicos presentes aqui. É discutindo a teoria dos signos que Deleuze vai caracterizar o aprender como um "encontro com signos".

Aprender diz respeito essencialmente aos signos. Os signos são objeto de um aprendizado temporal, não de um saber abstrato. Aprender é, de início, considerar uma matéria, um objeto, um ser, como se emitissem signos a serem decifrados, interpretados. Não existe aprendiz que não seja "egiptólogo" de alguma coisa. (DELEUZE, 2003, p. 4)

A sequência do raciocínio interessa ainda mais à discussão em curso. Escreve Deleuze:

Nunca se sabe como uma pessoa aprende; mas, de qualquer forma que aprenda, é sempre por intermédio de signos, perdendo tempo, e não pela assimilação de conteúdos objetivos. Quem sabe como um estudante pode tornar-se repentinamente "bom em latim", que signos (amorosos ou até mesmo inconfessáveis) Ihe serviriam de aprendizado? Nunca aprendemos alguma coisa nos dicionários que nossos professores e nossos pais nos emprestam. O signo implica em si a heterogeneidade como relação. Nunca se aprende fazendo como alguém, mas fazendo com alguém, que não tem relação de semelhança com o que se aprende. (DELEUZE, 2003, p. 21).

Deleuze indica que aprender é um acontecimento que se dá em função do encontro com um problema que nos força a pensar. É esse aspecto que estimula Deleuze a afirmar que aprender não está vinculado à recognição, mas à criação de algo novo, ao que está associado uma certa imprevisibilidade que coloca em xeque a própria pretensão de a pedagogia moderna ser uma ciência e mesmo a possibilidade de planejar, controlar, medir os processos de aprendizagem. "Aquilo que a pedagogia controla é aquilo que o professor pensa que ensina, seu currículo, seus conteúdos e suas técnicas; mas para além deste aprendizado quantificável e quantificado, há como que um “aprender quântico"”, (GALLO, 2012, p. 5).

Outro aspecto da reflexão deleuziana é que o aprender é fazer com o outro, e não fazer como, imitar o outro.

Aprendemos com a convivência, com a presença, com o corpo todo; Deleuze afirma que no aprender "não há ideomotricidade, mas somente sensório-motricidade", isto é, que aprender não implica em um movimento na ideia, mas sim em um movimento na sensibilidade, no corpo. (GALLO, 2012, p. 6 e 7).

Assim, aprender é sempre encontrar-se com o outro, com o diferente, a invenção de novas possibilidades; o aprender é o avesso da reprodução do mesmo. Segundo Deleuze isso se dá porque aprender é relacionar-se com signos; eles, como problemas, pedem uma resposta, e esta é sempre singular, inovadora.

\footnotetext{
${ }^{1}$ Deleuze não se dedicou especificamente à educação, mas em dois de seus livros (Proust e os Signos e Diferença e repetição) ele desenvolve uma reflexão que segue numa direção diferente da tradição ocidental.
} 
As comunidades de práticas são lócus de experiências nas quais a dinâmica de aprendizagem não separa o saber do fazer - como a educação escolar o faz (TAVARES \& MESQUITA, 2019). Os elementos pedagógicos com tecnologias da informação e comunicação aqui sugeridos perpassam as noções de encontro, congraçamento, articulação - são baseados na ideia-conceito da relação (GLISSANT, 2005): a disposição a encontros entre pessoas, mas também de pessoas com objetos técnicos e com narrativas sobre seres míticos.

\section{Corpos que emanam afetos}

Com isso, essa reflexão considera, no geral, como os diferentes contextos em que vivem esses sujeitos, como as marcas sobre suas etnias, as crenças que acionam deveres, como os corpos que emanam afetos, como amores e ódios vividos agenciam saberes e aprendizados tecnológicos que sirvam à produção de narrativas afrocentradas. Mas essa reflexão aciona, de forma mais específica, o campo e personagens do Candomblé como elementos pedagógicos para a aprendizagem com tecnologias - o que será detalhado mais à frente.

Assim, a reflexão é direcionada à experiência afrodescendente no Brasil. É dos sujeitos negros e não-brancos e de sua produção simbólica livre (narrativas) em meio digital que se parte. É a partir dos sujeitos pretos e pardos e das limitações que enfrentam em relação à produção e fruição de informação, cultura e conhecimento que se inicia. Como bem lembra Luiz Rufino (2019, p.131), “Combater o esquecimento é uma das principais armas contra o desencante do mundo. O não esquecimento é substancial para a invenção de novos seres, livres e combatentes".

O não esquecimento demanda narrativas que circulem e acionem novas narrativas. Isso exige, por outro lado, um saber-fazer variado. É aqui que uma pedagogia de fresta com tecnologias se presta a esse objetivo mencionado por Rufino, de recuperação, reconstrução, invenção e criação. A principal referência será a ancestralidade.

A procura pela compreensão e sistematização das metodologias, estratégias e táticas de uso de redes sociais, hardwares e softwares livres, linguagens de programação, gameficação, dados e narrativas a partir de perspectivas afro-brasileiras tem indicado a necessidade e a conveniência de uma, já mencionada, abordagem afro-centrada - em particular a partir das contribuições de Molefi Kete Asante, Cheik Anta 
Diop e Abdias Nascimento. Também têm sido mobilizados elementos da filosofia afroperspectivista, para a qual Renato Nogueira (2011) tem dado enorme contribuição.

No processo da pesquisa que resulta neste texto, foram inicialmente levantadas questões como estas: quais são os saberes e práticas que subvertem a ambiência logo-técnica que produz as tecnologias de controle e o fim da privacidade? Quais são as linhas identificáveis de uma pedagogia da subversão das técnicas do contemporâneo? Quais são os elementos necessários para a emergência de pedagogias populares do objeto técnico que sejam emancipadoras? (DA COSTA JR, 2016).

Observe-se que essas questões não colocam clara e diretamente o contexto, os corpos, a relação com o outro, a identidade e os afetos. De modo que, até o presente artigo, o trabalho indicava um caminho (e uma bibliografia) eurocêntricos - ainda que as apostas conceituais já considerassem a possibilidade de o pensamento (e, portanto, o aprendizado com tecnologias) ser considerado uma experiência; e o sentido do objeto técnico, um acontecimento (LÓPEZ, 2008).

Essa articulação apontava para uma sucessão de estados metaestáveis em que o objeto técnico é pensado e transformado, apropriado e ressignificado por práticas artesãs. O objeto técnico pensado por Simondon (2020) e retomado por Deleuze, a importância da leitura dos dispositivos técnicos como signos, a ideia de devir, de acontecimento, o aprendizado pela experiência de Jorge Larossa e as subversões sugeridas por Agamben (2009) foram elementos mobilizados ${ }^{2}$ e sugerem a existência de uma semiótica da subversão das técnicas e das tecnologias a ser aprendida - e, portanto, uma pedagogia, mas que não necessariamente deva depender de um programa formal de aprendizagem escolar, ou seja, um programa institucionalizado nas redes de ensino.

A associação de novos elementos analíticos ${ }^{3}$ tornou possível perceber a necessidade de discutir a elaboração de um programa de aprendizado afrocentrado a partir da localização psicológica, cultural, histórica ou individual ocupada por uma pessoa em dado momento da história (ASANTE, 2009). Como sabemos, essa localização aponta para uma condição secular de marginalidade das populações negras, de margem. Entretanto,

\footnotetext{
2 No artigo mencionado (DA COSTA JR, 2016), argumentava-se que os objetos técnicos poderiam ter sentidos e funções diferentes, de acordo com diferentes situações e contextos, em diferentes experiências pelas quais passam as pessoas a manipulá-las, e era nesse sentido que a subversão se fazia.

${ }^{3}$ A inflexão da pesquisa em andamento em direção aos estudos pós-coloniais e afrocentricidade é, também, expressão de um processo de autorreflexão do autor sobre identidade, posição psicológica e cultural, e agência.
} 
a margem não deve ser vista apenas como um espaço periférico, um espaço de perda e privação, mas sim como um espaço de resistência e possibilidade. A margem se configura como um espaço de abertura radical e criatividade, onde novos discursos críticos se dão. É aqui que as fronteiras opressivas estabelecidas por categorias como "raça", gênero, sexualidade e dominação de classe são questionadas, desafiadas e desconstruídas. Nesse espaço crítico, podemos imaginar perguntas que não poderiam ter sido imaginadas antes; podemos fazer perguntas que talvez não fossem feitas antes, perguntas que desafiam a autoridade colonial do centro e os discursos hegemônicos dentro dele (KILOMBA, 2019, p. 68).

As resistências e possibilidades associadas às margens, que Kilomba menciona, expressam a emergência e a credibilização de saberes, "comprometidos, agora, com o reposicionamento histórico daqueles que os praticam", como afirma Luiz Rufino (2019, p. 23). Essa associação é cheia de sentidos para esta pesquisa, como se verá.

Como propõem Mesquita e Ramallo (2018), uma das marcas da educação moderna é a mediação, que atua como um dispositivo de colonização e esterilização da imaginação em sua (im)possibilidade de (re)inventar, (re)criar e (re)imaginar "outros mundos possíveis".

O aprendizado tecnológico e, em particular, o aprendizado com tecnologias da informação e comunicação numa sociedade hipermediada também são trespassados pela mediação, que atua como um dispositivo de colonização e esterilização da imaginação. Assim como outras áreas da educação moderna, o aprendizado tecnológico é guiado por um imaginário específico e, como tal, está condicionado pela noção de universalização da cultura eurocêntrica e ocidental.

O uso do termo 'dispositivo' não é casual. A mediação enquanto tal se refere a um mecanismo de captura dos desejos e das marcas próprias da subjetividade humana. Como tal, a mediação se constitui enquanto uma esfera apartada do ser. Essa característica ganha ainda mais relevo se lembrarmos que o conjunto crescente de serviços, plataformas e produtos baseados em tecnologias da informação e comunicação também modula o comportamento, impondo práticas, hábitos, crenças por meio de processos de governamentalidade algorítmica.

Em oposição a essa matriz pedagógica, estão as narrativas decoloniais e os saberes de fresta e ancestrais (RUFINO, 2019), que expressam outras racionalidades para além do dispositivo da mediação pedagógica. Entre essas racionalidades, estão por exemplo a mítica da produção conhecimentos no entorno do Baobá (MESQUITA, 2013) ou as metodologias de gameficação a partir dos Orixás (TEIXEIRA \& PINTO, 2019), entre muitas outras. 
O que é preciso lembrar é que a mediação tem, em sua espinha dorsal, um modelo tutelar, que dá o tom da relação entre colonizadores e colonizados e que impõe como universal valores morais, racionais e intelectuais. Em relação ao aprendizado com tecnologias da informação e comunicação, esse modelo expressa um imaginário no qual a tecnologia é vista como um universal (HUI, 2020), o que implica formatos padrões de relacionamento e uso, mas também uma única linha evolutiva das tecnologias.

Seguindo a sugestão de Grada Kilomba, o caminho de pensamento e de investigação, no que se refere aos temas até aqui mencionados, reivindica a necessidade de desenvolver ou sistematizar formas de aprendizado tecnológico que contribuam, em alguma medida, para que pessoas negras entrem na luta como sujeitos, e não como objetos (HOOKS, 1994, p. 7).

\section{Lugar, agência e quilombismo}

O trabalho de desenvolvimento de pedagogias para lidar com esse contexto e essas necessidades parece exigir, como já indicado, uma abordagem centrada nas pessoas submetidas a essa atualização. A afrocentricidade parte da afirmação de que a compreensão dos fenômenos se articula e ganha contornos especiais de acordo com a identidade do sujeito. Assim, trata-se de definir a localização psicológica, cultural, histórica ou individual ocupada por uma pessoa em dado momento da história. O interesse pela localização psicológica faz parte de um conjunto de características mínimas para um projeto pedagógico afro-cêntrico com tecnologias.

Esse princípio da abordagem afro-centrada, subjacente também no pensamento feminista, já fora assinalado no Brasil na década de 1950, no contexto da produção intelectual do Teatro Experimental do Negro. Emerge como alicerce de uma tendência mundial no Século XX de estabelecer a identidade como questão social e fator político. (NASCIMENTO, 2009, p. 182)

Esse ponto de partida tem uma conexão forte com o princípio filosófico que ampara o trabalho de desenvolver pedagogias afro-centradas para lidar com o ambiente sociotécnico contemporâneo adotado aqui - uma filosofia afroperspectivista, cujos elementos constitutivos sejam um plano de imanência afroperspectivista, a invenção de personagens melanodérmicos e a criação de conceitos afroperspectivistas (NOGUEIRA, 2011). Esse aspecto é desenvolvido no tópico seguinte.

As características mínimas mencionadas acima ainda ressaltam a agência: a capacidade de dispor dos recursos psicológicos e culturais necessários para ser ator ou protagonista em seu próprio mundo. Essa orientação aciona a necessidade de "estar atento a tudo e procurar escapar à anomia da exclusão", como 


\section{ALCEU}

ISSN: $2175-7402$

afirma Asante (2009, p. 95). Se este é um problema linguístico, representa também um desafio, direcionado fundamentalmente ao eu coletivo, de enfrentar a realidade de situações econômicas e culturais previamente construídas.

O que os africanos fazem no Brasil, na Colômbia, na Costa Rica, na Nicarágua, no Panamá, na Venezuela, nos Estados Unidos, na Nigéria, em Gana, em Camarões, no Congo e na França é parte de uma ascenção geral e coletiva à consciência, na medida em que tenha como objetivo o processo de libertação, (ASANTE, 2009, p.104)

No sentido dessa discussão, parece necessário atentar a um instrumento conceitual operativo que organiza meios de a gente negra defender sua sobrevivência física e cultural. Tal modelo associativo se desenvolveu no país e se atualiza como ideia-força há quatro séculos, assumindo as formas legais de rede de irmandades, confrarias, clubes, grêmios, terreiros, centros, tendas, afoxés, escolas de samba e gafieiras. A despeito das diferenças entre $\mathrm{si}^{4}$, formaram uma unidade de afirmação humana, étnica e cultural que integrou uma prática de libertação e de autonomia. A essa práxis, Abdias Nascimento (1980) deu o nome de quilombismo.

Dada a importância que essa instituição desenvolveu e desenvolve na vida da população negra afrodescendente no Brasil, parece difícil desconsiderar o papel que o quilombismo pode ter associado aos processos de aprendizagem no contexto atual. Na verdade, alguns dos grupos que atuam com produção de narrativas em rede já acionam elementos de um quilombismo reatualizado.

Abdias Nascimento entendia que a prática quilombista construiu um patrimônio que precisa ser mantido e ampliado. Dessa ideia-força, dependeria, para Nascimento, um futuro melhor para a população afro-brasileira. Adequadamente, o autor afirma que a prática quilombista, qualquer que seja sua expressão, mobiliza as energias, as inteligências e as capacidades escolarizadas "para a enorme batalha no front da criação teórico-científica" (NASCIMENTO, 2002, p. 47).

\section{Roda, quebrada, campo de imanência}

A discussão de como incluir vozes africanas e ameríndias nas áreas da filosofia e da educação é que, em última instância, produziu a expressão filosofia afroperspectiva e seus sentidos. A filosofia afroperspectivista, que guia o desenvolvimento de elementos pedagógicos, é uma composição em termos

\footnotetext{
${ }^{4}$ Abdias Nascimento observa que as organizações permitidas ou toleradas foram concomitantes às proibidas, localizadas em áreas distantes - o que facilitava sua defesa e sua organização econômico-social.
} 
deleuzianos $^{5}$. O que se propõe neste artigo, como já afirmado, é a discussão de uma linha filosófica que articule os aprendizados com tecnologias digitais e elementos das histórias e culturas afro-brasileiras e africanas.

Essa articulação parte da experiência, como já indicado antes: invenções, criações, adequações de devires negros são acionados para construir protagonismo que coloque a vida das populações negras no centro dessa discussão.

Deleuze e Guattari afirmam que o que caracteriza a filosofia são três elementos: criar conceitos, traçar um plano de imanência e inventar personagens conceituais. Na filosofia afroperspectivista, tais traçados, invenções e criações devem atender à perspectiva Africana ${ }^{6}$. A filosofia, assim definida como criação de conceitos, implica uma pressuposição que dela se distingue, e que, todavia, dela é inseparável. A filosofia é ao mesmo tempo a criação de conceitos para lidar com problemas específicos e a instauração do plano de imanência - e isso também vale para a filosofia afroperspectivista.

Mas o que é o plano de imanência exatamente? Usando as palavras de Deleuze, todo plano de imanência pode ser lido como "um corte do caos e age como um crivo" (DELEUZE \& GUATTARI, 1992, p. 52). É o campo onde os conceitos circulam, se entrechocam, fazem sentido para tratar de certos problemas. Deleuze o define ao mesmo tempo como horizonte e como solo. Como solo, o plano de imanência é o terreno intuitivo, onde habitam elementos pré-filosóficos. Como horizonte, o plano de imanência corresponde à imagem do pensamento. Assim, a consistência, as características do plano de imanência têm um forte vínculo à imagem do pensamento e a elementos externos (mas não estranhos) à filosofia mesma.

A afroperspectividade é uma imagem do pensamento da filosofia afroperpectivista, o plano, o solo, a roda sobre a qual dançam os conceitos - daí a importância de discuti-la. Para Renato Nogueira (2011), a

\footnotetext{
${ }^{5}$ Como se sabe, o grande tema da obra de Gilles Deleuze é o pensamento - seu exercício e a possibilidade de novas formas do pensar que se contraponham ao que chamou de imagem dogmática do pensamento e suas teses. A tarefa da "filosofia do porvir", nome dado pelo autor, deve ser colocar movimento no pensamento, retirá-lo de sua imobilidade. Acontece justamente que o pensamento associado às formas convencionalizadas de aprendizagem com tecnologias tem proximidade com um certo estado de paralisia: a condição de usuário é passiva, destituída de movimento. Daí que pedagogias que se orientem pelo movimento acionem também forças, no que diz respeito ao que se pode fazer como protagonista e com base em um pensamento ativo, móvel.

${ }^{6} \mathrm{O}$ termo se refere a tudo que diz respeito à África e à sua diáspora - não significando, assim, o feminino de "africano". Trata-se do uso da forma plural em latim e indica, por um lado, os povos afrodescendentes no mundo todo e, por outro, a metodologia multidisciplinar, interdisciplinar e transdisciplinar dos estudos nesse campo.
} 
imagem do pensamento da filosofia afroperspectivista pode ser apresentada por estas três teses básicas: $1^{\text {a) }}$ Pensar é movimentação, todo pensamento é um movimento que, em vez de buscar a Verdade e se opor ao falso, busca a manutenção do movimento; $2^{\mathrm{a}}$ ) O pensamento é sempre uma incorporação, só é possível pensar através do corpo; $3^{\mathrm{a}}$ ) A coreografia e o drible são os ingredientes que tornam possível alcançar o alvo do pensamento: manter a si mesmo em movimento.

Os conceitos são assentados sobre esse solo pré-filosófico, que se refere à terra, aos movimentos de incontáveis desterritorializações e reterritorializações africanizantes e africanizadas, a uma fundação que pode ser um terreiro, uma roda, uma roça, como indica Nogueira (2011), mas também a quebrada, um beco, uma encruzilhada, a escadaria (onde acontecem as batalhas de hip-hop), os bailes funk.

Na presente reflexão, o que procuro é discutir alguns conceitos e inventar personagens conceituais em um plano de imanência formado pelo Candomblé de matriz nagô. É importante frisar que esse recurso se coloca como uma invocação filosófica (afroperspectivista), e não como uma convocação religiosa ou mística. E que tal movimento deve servir para orientar processos de identificação cultural e aprendizagem com tecnologias para a produção de narrativas afrorreferenciadas.

O Candomblé é uma experiência cultural complexa que integra de forma muito importante a afroperspectividade - entre outros elementos. O recurso a referências afro-brasileiras acionadas aqui lembra que noções tais como "a invenção de novas possibilidades", "criatividade", "abertura radical", “imaginação aberta” dialogam de maneira muito intensa com um personagem importante do imaginário brasileiro - Exu (na grafia Yorubá, 'Eșú' $)^{7}$ - e com um lugar-conceito (a encruzilhada).

Como elemento pré-filosófico do plano de imanência da afroperspectividade, Exu corresponde à energia que dá vazão aos acontecimentos, à possibilidade mesma da existência (de qualquer coisa, inclusive das pedagogias) e à fertilidade. Já a encruzilhada, a principal referência associada a esse Orixá, sinaliza a "disponibilidade para novos rumos, poética, campo de possibilidades, prática de invenção e afirmação da vida, perspectiva transgressiva à escassez" (RUFINO, 2019, p. 85).

Essa expressão mítica de possibilidades abertas é um dos principais dispositivos de aprendizagem pelos quais se pode acionar identificação popular com tecnologias para a produção de narrativas: ela

\footnotetext{
7 No restante do artigo, utilizo a grafia dos nomes dos Orixás e de oficiantes de culto (laloríxá e Babalorixá) como predominantemente são usados no Brasil, e não a grafia Yorubá.
} 
sinaliza que se pode fazer mais com os recursos disponíveis; que os dispositivos técnicos podem ser alterados e transformados em seus formatos, funções e propriedades; que a apropriação tecnológica, jargão já muito gasto nas iniciativas de inclusão tecnológica, é um termo que tem sua contrapartida na orientação exusíaca de deglutir tudo ao seu redor (conhecimentos, técnicas, metodologias) e, com isso, colocar para fora outra coisa ${ }^{8}$.

Estão postos, assim, limites das potências do objeto técnico (o que se pode fazer com as tecnologias para a produção de narrativas e como tais possibilidades podem ser inseridas num processo de aprendizagem). A obra de Simondon (2020) é uma importante referência, retomada em anos recentes, para pensar os limites das potências do objeto técnico. Sua obra ajuda a pensar os agenciamentos sóciotécnicos em termos de individuações ${ }^{9}$ em processo. Em seus termos, o processo de formação do indivíduo (a individuação, que abrange objetos técnicos) passa a ser compreendido como uma realidade em trânsito, uma determinada fase. É isso que abre possibilidades para a superação das perspectivas imobilizadoras tanto tecnofóbicas quanto tecnofílicas. Segundo Simondon, é possível e necessário pensar em suspensão da técnica como algo natural (positivo) ou artificial (negativo). E tomá-la como algo sobre o qual é ainda possível atuar - e, portanto, em processo. Nesse sentido, Simondon chama atenção para o trabalho do artesão, que é baseado numa organização analítica, deixando sempre a via livre a novas possibilidades (SIMONDON, 2020, p. 23).

Ao se considerarem os aparelhos técnicos em um processo de individuação, eles são "libertos" do modelo matéria-forma, o que implica sua separação do modelo atribuído pelo trabalho industrial definições essas advindas da relação causal e premeditada entre forma e matéria.

O que a teorização de Simondon, retomada por Deleuze, aponta é uma busca do objeto técnico, busca pela apreensão e apropriação do objeto técnico, que permite que a operação tecnológica seja separada do modelo de trabalho estanque, passando a se sujeitar a operações, a movimentos de

\footnotetext{
${ }^{8}$ Enugbarijó, a boca que tudo engole e vomita o que tudo engoliu de forma transformada, é uma das representações de Exu, descrita por inúmeros autores, como Reginaldo Prandi (2001) e Luiz Rufino (2019).

${ }^{9} \mathrm{O}$ autor desenvolve um entendimento segundo o qual o indivíduo não é o correspondente a uma unidade atômica, constituída de um núcleo de permanência estável, que resiste e subsiste por si só. Da mesma forma, os seres individuais não são resultado ou o composto formado pelo par matéria/forma. Como importante referência para Bruno Latour, Simondon pensa a formação dos seres - orgânicos ou físicos - em termos de um desenvolvimento de um processo mais complexo: a gênese do indivíduo deve ser explicada no princípio de individuação. Simondon opera uma subversão na investigação da gênese do indivíduo ao voltar seu olhar para o processo, para a zona obscura de formação, e não para o indivíduo já constituído e o real individuado.
} 


\section{ALCEU}

ISSN: 2175-7402

deformação, a deslocamentos que se aproximam mais de uma modulação do que de uma moldagem. A chave de leitura dessas possibilidades através do personagem Exú permite um acesso com mais identificação e reconhecimento, em especial nos contextos para os quais se dirige o esforço dessa reflexão ${ }^{10}$.

\section{Personagens conceituais melanodérmicos}

Alguns dos personagens conceituais melanodérmicos são a lalorixá, o Babalorixá, o griot, o bamba, a(o) jongueira(o), todos os Orixás (Exu, Oxalá, Obatalá, Ogum, Oxóssi, Oxum, Xangô, Ossaín, Yemanjá, entre outros.), inquices (Ingira, Inkosi, Mutacalambô, Gongobira etc.), Voduns (Dambirá, Sapatá, Heviossô etc), entre muitos outros (NOGUEIRA, 2011, p. 4). Tais personagens, inclusive as representações divinas, possuem relação com tipos psicossociais e atitudes relacionais que podem ser acionados em uma determinada sociedade (DELEUZE, 1992, p. 85).

Ao mesmo tempo, os personagens conceituais nada têm a ver com uma personificação abstrata, um símbolo ou uma alegoria"11, pois, como afirma Deleuze, "ele vive, ele insiste" (DELEUZE, 1992, p. 86). Os personagens conceituais melanodérmicos, assim, operam os movimentos que descrevem a afroperspectividade (plano de imanência) e intervêm na própria criação dos conceitos. Ou seja, os personagens conceituais melanodérmicos são os agentes da enunciação da filosofia afroperspectivista que ampara uma matriz pedagógica correspondente.

No contexto dessa reflexão, essa característica tem várias consequências, na medida em que os tipos sociais que inspiram os personagens conceituais existem por causa, justamente, de processos de territorialização, desterritorialização e reterritorialização, evidentemente vinculados às diásporas negras. Deleuze afirma que os personagens conceituais são pensadores, unicamente pensadores, e seus traços personalísticos se juntam estreitamente aos traços diagramáticos do pensamento e aos traços intensivos dos conceitos.

Por exemplo, se dizemos que um personagem conceituai gagueja, não é mais um tipo que gagueja numa língua, mas um pensador que faz gaguejar toda a linguagem, e que faz da gagueira o traço do próprio

\footnotetext{
10 Não é possível aqui esgotar as possibilidades de articulações de ordem tecno-filosófica entre Exú e a perspectiva de Simondon. Mas há um caminho rico de diálogo a ser explorado e que será tanto mais rico quanto puder ter incidência nas formas pelas quais se aprende e se ensina a lidar com as TICs.

11 "estes personagens se tornam, eles mesmos, coisa diferente do que são historicamente, mitologicamente ou comumente (o Sócrates de Platão, o Dioniso de Nietzsche, o Idiota de Cusa)” (DELEUZE, 1992, p. 86).
} 
pensamento enquanto linguagem: o interessante é então "qual é este pensamento que só pode gaguejar?". Por exemplo, ainda, se dizemos que um personagem conceituai é o Amigo, ou então que é o Juiz, o Legislador, não se trata mais de estados privados, públicos ou jurídicos, mas do que cabe de direito ao pensamento e somente ao pensamento. Gago, amigo, juiz não perdem sua existência concreta, ao contrário, assumem uma nova existência, como condições interiores do pensamento para seu exercício real, com tal ou tal personagem conceituai. (DELEUZE, 1992, p. 92)

Se dizemos que um personagem conceitual é Oxum, Ogum ou Exu, de que falamos? A escolha desses Orixás não é casual, como se evidenciará. "Se a civilização ocidental propõe à mulher um estereótipo feminino calcado na docilidade e na submissão, o Candomblé tem sua contrapartida em Oxum (a mais bela iyabá, a mulher por excelência" (CARNEIRO, 2019, p. 68). Entretanto as leituras coloniais desse personagem sugerem Oxum apenas como mãe, portanto vulnerável, disputando o amor de Xangô, eliminando suas concorrentes. As leituras coloniais não a veem como Yalodê - autoridade maior do espaço público, mãe não binária, força de criação (não somente para parir crianças), potência da mente: foi Oxum quem iniciou o primeiro ser humano no Axé (entendido aqui como força vital).

São elementos assim que essa reflexão procura utilizar no sentido do desenvolvimento de pedagogias afro-centradas com tecnologias. Um dos Odus de Ifá12 conta como Oxum se rebela contra os Orixás, homens que haviam se reservado ao privilégio de receber os ebós ${ }^{13}$. Esse sistema reservava às Orixás mulheres o trabalho de cozinhar as oferendas. Diante do desequilíbrio dessa distribuição, Oxum anuncia um castigo a todos. Daquele dia em diante não nasceriam mais pessoas no Ayê ${ }^{14}$. Com o tempo, as pessoas deixariam de nascer e, à medida que o tempo passasse, os Orixás seriam esquecidos ou deixados de ser cultuados e alimentados.

Consultado pelos Orixás, Olorun (o Deus supremo) explicou que o desentendimento havia sido causado por eles mesmos, ao não acolherem uma Orixá feminina para repartir as oferendas: o esquecimento e a falta de respeito à Oxum - e, consequentemente, a todas as Orixás - provocaram o justo ressentimento com o desequilíbrio da ordem pública. A solução seria trazer Oxum para participar dos rituais de sacrifício.

Oxum convida os orixás masculinos para uma negociação, impondo uma pauta surpreendente. Ela está dizendo algo como: "O meu trabalho é facultativo, não compulsório. Meu corpo é meu, a gravidez é minha escolha". Por isso, a bela imagem de que a fertilidade do mundo cessou pela vontade de Oxum pode

\footnotetext{
12 O Ifá é o nome dado ao sistema de divinatório Yorubá. Os Odus são contos filosóficos que formam o corpo do Ifá e são acionados por babalawos no jogo do meridilogun (búzios).

${ }^{13}$ Oferendas. É em torno dos ebós às dividades que se estabelece a complexa teogonia Yorubá (SANTOS, 2002, p. 15).

${ }^{14}$ Parte da criação onde vivem os vivos - tanto os com corpo, quanto os desincorporados.
} 
remeter à desnaturalização da função de parideira intermitente associada à imagem da mulher. (NOGUEIRA, 2017, p. 75)

Mas, entendida aqui como personagem, Oxum diz algo mais: reclama por direitos iguais na gestão do espaço público. Nesse sentido, afirma que também tem direito a receber o produto das oferendas. Reivindica o cuidado, mas uma disposição para um cuidado que se projeta para o espaço público, para o fora, para a relação entre as pessoas - na medida em que mudanças internas, no entorno do privado, podem ter reflexo sobre o espaço público. Mais ainda: afirma que essa disposição para o cuidado deve ser compartilhada por homens e mulheres. Ou seja, realiza uma recusa aos caprichos masculinos e a um mundo cujo espaço público é por eles inteiramente regulado. A personagem afirma, afinal, a necessidade de se equilibrarem as forças que regem o espaço comum - no que diz respeito à divisão de tarefas e de trabalho, mas também de ganhos e reconhecimento. O que se sobressai aqui, então, é uma personagem que manuseia tecnologias do cuidado, mas que, em sua coerência com a origem do mito Yorubá, transborda as leituras coloniais que apontam Oxum como mera rainha amorosa da beleza e da maternidade.

Um outro Odú, também relativo à deusa Oxum, me parece adequado para ilustrar o uso de personagens melanodérmicos como intercessores de processos de aprendizagem com tecnologias para a produção de narrativas. Oxum e Yansan eram as esposas preferidas de Xangô. As duas se estranhavam e procuravam não dividir os mesmos espaços. Até que, num dia, Yansan resolveu usar sua espada em Oxum, que se banhava num lago. Usava seu espelho (abébé), por meio do qual viu Yansan se aproximando. Com o espelho, fez cegar a guerreira Yansan e escapou.

O que a personagem nos diz com essa história? Que o espelho não serve para enxergar somente a si própria, mas também para refletir sobre o que está ao seu redor. E que tal dispositivo, mais comumente relacionado a um símbolo de vaidade, pode ser uma ferramenta de intervenção na realidade.

Oxum mostra que é possível tomar o reflexo como uma potência defensiva. Nesse sentido, engana-se quem faz a leitura superficial de que o espelho da deusa serve para que ela cultive e aprofunde sua própria vaidade. $O$ espelho é um signo que revela mais a respeito da reflexão sistemática diante da vida que um esforço para tornar-se bonita. Oxum apodera-se para agir em favor de sua proteção contra outras mulheres e homens que a atacam (NOGUEIRA, 2017, p. 94-95).

É interessante observar que o "empoderar-se" da citação se refere a investir poder a si mesma, o que é diferente de empoderar, verbo transitivo direto, que significar receber autorização de outrem para ter poder. $O$ espelho de Oxum não se restringe à interpretação colonial segundo a qual ele seria um 


\section{ALCEU}

ISSN: $2175-7402$

instrumento da vaidade, a que se vinculam os recursos das maquilagens faciais. A deusa se ocupa de outras táticas, às quais Nogueira adequadamente se refere como "maquilagens de guerra": "Diante de um cenário hostil, um mundo de conflitos declarados e implícitos, seu espelho é uma arma de defesa. A sua inteligência mantém a consciência e atenção alertas" (NOGUEIRA, 2017, p. 95). Como personagem melanodérmica, Oxum fala da necessidade de autoconhecimento para a reflexão sobre o ambiente.

Além de Exu e Oxum, cabe tratar, ainda que brevemente, de Ogum e das potências associativas que esse personagem melanodérmico sugere. O Orixá, irmão de Exu, "governa o ferro, a metalurgia, a guerra. É o dono dos caminhos, da tecnologia e das oportunidades de realização pessoal" (PRANDI, 2001, p. 23). Se Exu é o Orixá da comunicação e do movimento, Ogum é a entidade da conexão, o que significa que ele preside a invenção e o funcionamento dos equipamentos e dos dispositivos técnicos. Ogum é aquele que traz consigo as tecnologias, os recursos práticos de transformação, as ferramentas e os meios que tornam possível às ideias tomarem corpo.

Conta um dos Odus que Oxaguiãn, a invocação ou versão jovem de Oxalá, uma vez procurou Ogum aflito: seu reino crescia demandando a construção de novas casas, crianças nasciam todos os dias e mais bocas surgiam para alimentar. Era necessário intensificar os meios para aumentar a produção de alimentos, mas também para construir mais e melhores habitações. É essa história (narrativa, em Yorubá, ìtàn) que conta a invenção das ferramentas agrícolas e também dos meios técnicos necessários para o crescimento e desenvolvimento urbano, vindos das potências de Ogum. O Orixá, assim, representa as possibilidades de realização de ideias ou de necessidades dos homens - e dos deuses também. Essa é a faceta do ferreiro, do inventor, do habilidoso criador.

Outra faceta de Ogum é a da guerra e do guerreiro. Os Odus do Orixá indicam que a guerra de Ogum serve para movimentar e transformar aspectos variados de determinada situação. Ainda assim, estão coladas a esse personagem melanodérmico a destruição, a morte e a violência da guerra, ainda que esta seja deflagrada para a transformação.

Um dos Odus mais populares do Orixá relata que, após sua conquista do reino de Irê, Ogum resolve viajar. Depois de algum tempo ausente de seu reino, volta à cidade-Estado, mas não consegue conversar com nenhum de seus súditos, que o ignoram em todas as situações. Isolado, Ogum sente-se traído, o que desencadeia sua ira, exterminando boa parte da população. Ogum não sabia, entretanto, que o reino 
estava em voto de silêncio, que fazia parte de uma cerimônia religiosa. Ao perceber seu engano, Ogum abdica do trono em favor de seu filho e vai morar nas estradas. Noutra versão, envergonhado e entristecido pelo que fez, Ogum finca a espada no chão e desaparece.

Há, ainda, um Odu no qual Ogum se cansa do trabalho de ferreiro e se isola na mata, recusando-se voltar ao convívio com as pessoas. As coisas acabam sucedendo mal com esse afastamento, porque as máquinas, utensílios e dispositivos inventados por ele começam a precisar de reparos e a faltar, para as mais diversas atividades. A volta de Ogum ao convívio só acontece pela intervenção de Oxum.

Os Odus mostram, para diferentes facetas do Orixá, como o isolamento e o ensimesmamento daquele que lida com as tecnologias (das conexões, do trabalho ou da guerra) causam desequilíbrios à comunidade. O que restaura a ordem das coisas, nesses Odus que tão bem representam a natureza do Orixá, é a percepção do outro, é a reconexão com as pessoas.

O que uma pedagogia afro-centrada nos moldes do que se discute aqui pode efetivar é essa chave associativa entre os deuses do Candomblé Nagô e o alargamento das possibilidades narrativas, como também os processos de aprendizagem das tecnologias.

\section{Conceitos e problemas afroperspectivistas}

Utilizo essas histórias como gancho para o argumento central desta reflexão. Os mitos podem ser estratégias muito produtivas para interpretações psicológicas e filosóficas da ação dos homens e das mulheres, pois revelam aspectos sociais, antropológicos e históricos da sociedade. Ou seja, revelam formas pelas quais a personalidade, a individualidade, a identidade são formadas no confronto com "o fora", e, assim, funcionam como chaves de leitura e de intervenção da realidade. Não por acaso, os campos da psicologia e da psicanálise se apoiam nos mitos - majoritariamente, é claro, ocidentais.

Para além disso, as referências míticas também podem servir como caminhos para formas de aprendizado e de relacionamento com os dispositivos técnicos necessários à produção, à circulação e ao consumo de narrativas variadas por parte das populações afrodescendentes no Brasil. É nesse sentido que o terceiro elemento de uma filosofia afroperspectivista que ampare pedagogias afro-centradas com tecnologias da informação e comunicação deve ser acionado. Há um conjunto de problemas passíveis de serem analisados sob a perspectiva afrodiaspórica, no que se refere à produção de narrativas e ao domínio 
das técnicas necessárias para isso acontecer em espaços virtuais. É necessário se referir a esses desafios antes de apontar conceitos de pedagogias afro-centradas com tecnologias, pois os conceitos só fazem sentido devido aos problemas de que procuram dar conta (DELEUZE, 2003).

O formato atual do capitalismo atualiza as centenárias formas de extração de valor em geral (COULDRY \& MEJIAS, 2019), mas, especificamente em relação às pessoas negras das diásporas, também atualiza as formas de exclusão, marginalização e silenciamento. Quais tecnopolíticas podem ser acionadas para se contrapor a tais atualizações? Quais elementos culturais e psicológicos podem ser acionados para desenvolver essas tecnopolíticas e os correspondentes aprendizados?

Um obstáculo básico que grande parte das populações pretas enfrentam são as condições precárias ou inexistentes de acesso a tecnologias da informação e comunicação. É verdade que o número de usuários com acesso à internet alcançou, ao longo da primeira década deste século, mais da metade da população (CETIC, 2018), alcançando a base da pirâmide social ao final da primeira década. Mas a questão que se coloca é: como o acesso, notadamente móvel, vem sendo adotado e usado pelas populações afrodescendentes?

O movimento negro tem ocupado espaços na internet por meio de um variado espectro de estratégias e políticas comunicacionais. Como outras ações coletivas também o fazem, entidades do movimento ${ }^{15}$ combinam e complementam o uso de tecnologias da informação e comunicação a ferramentas tradicionais de articulação, produzindo continuidades, justaposições e rupturas entre gêneros, estéticas e linguagens. O estudo netnográfico desenvolvido por Denise Cogo e Sátira Machado (2010) evidencia essas experiências nas quais

Websites, portais, blogs, jornais e boletins online e impressos, rádios analógicas e digitais, documentários, redes sociais como Orkut, Facebook, Twiter etc., se combinam, para constituírem práticas comunicacionais do movimento negro que estão em consonância, em certo sentido, com o caráter de fluxo da sociedade da informação e da expansão das chamadas mídias digitais (COGO \& MACHADO, 2010).

\footnotetext{
${ }^{15}$ São exemplos o Afrobrass, organização paulista fundada em 1997 e voltada a atividades na área das ações afirmativas. Em 2002, criou o Instituto Afro-Brasileiro de Ensino Superior e instituiu, com licença do Ministério da Educação, a Universidade da Cidadania Zumbi dos Palmares (Unipalmares), primeira do Brasil e da América do Sul voltada para a inclusão no negro na vida acadêmica. Ouras iniciativas mapeadas são a Mídia Étnica da Bahia (http://www.midiaetnica.ning.com), a Agência de Informação Multiétnica (http://www.afropress.com), o Centro de Estudos Afro-Orientais (http://www.ceafro.ufba.br), e o portal de jornalismo colaborativo Correio Nagô (http://www.correionago.com.br)
} 
Entretanto, as diferenças no acesso à internet e seus recursos, por parte da população de pretos e pardos, reproduzem e reforçam as desigualdades na sociedade brasileira - cujo fator racial é estruturante dessas diferenças (AQUINO, 2013). A assimetria que se observa atinge pretos e pardos não associados diretamente a movimentos sociais e evidencia desigualdades que uma pedagogia popular afro-centrada, discutida neste artigo, procura minimizar.

Um dos primeiros estudos a expor essas condições foi produzido ainda em 2007 pela Rede de Informação Tecnológica Latino-Americana (RITLA), em parceria com o Instituto Sangari e o Ministério da Educação. No trabalho, o autor mostra como, em 2005, a condição de raça ou cor incidia nas condições de acesso

No país como um todo, $28,3 \%$ dos brancos de 10 anos e mais de idade manifestaram ter usado a Internet nos 3 meses anteriores à pesquisa. Já entre os negros, esse percentual cai para 13,3\%. Noutras palavras, brancos acessam a Internet 2,1 vezes mais que os negros, isto é, mais que o dobro que negros (WAISELFISZ, 2007. p.15).

O relatório mostrava ainda que "que as brechas internas - por renda, raça/cor, região geográfica do país - são muito mais largas e profundas do que as brechas que separam o Brasil dos países avançados", (WAISELFISZ, 2007, p. 5).

A literatura especializada tem mostrado as disparidades geográficas no acesso e uso de computadores e da Internet no Brasil desde meados da década de 1990. Como aponta Bernardo Sorg e Luís Eduardo Guedes (2008), há limitações para analisar a medida da exclusão digital nesses termos, porque a) o tempo disponível e a qualidade do acesso afetam, decisivamente, o uso da Internet; b) as tecnologias de informação e comunicação exigem uma frequente atualização de hardware e software para não ficarem obsoletos, o que demanda investimentos constantes dos usuários; c) seu potencial de utilização depende da capacidade de leitura e interpretação da informação.

Entretanto, o trabalho do Centro Regional de Estudos para o Desenvolvimento da Sociedade da Informação (Cetic.br), evidencia as diferenças entre as macrorregiões do país, e também entre as áreas urbanas e rurais, com algumas informações suplementares que vão além do número de acessos e que contribuem com essa discussão.

Os dados mais recentes da pesquisa TIC Domicílios 2019, desenvolvida pelo Cetic.br (CGI.br, 2020), mostram que hoje, no Brasil, 20 milhões de lares não possuem acesso à Internet, que houve uma redução 


\section{ALCEU}

ISSN: $2175-7402$

da presença dos computadores nos domicílios desde 2014 e que há uma grande diferença por classe social entre moradias com e sem computadores. Também é grande a diferença entre classes no que se refere ao acesso à rede: $95 \%$ das residências da Classe $\mathrm{A}$ estavam equipadas com algum dispositivo computacional (notebook, computador de mesa ou tablet). Entre a população das classes C e D, o percentual era de $44 \%$ e $14 \%$, respectivamente.

O estudo também mostra desequilíbrio no acesso à internet e em seus usos. Em 2019, 80\% das residências das classes $C$ possuíam acesso à internet, enquanto nas classes D e E o percentual era de apenas 50\%. A Classe A mantém, desde 2017, um percentual de 99\% de residências equipadas com acesso à grande rede de computadores. No total, $71 \%$ dos lares brasileiros se conectam à rede - o Nordeste tem o menor percentual, com $65 \%$ de residências conectados.

Esses dados, aliás, estão em sintonia com a Pesquisa Nacional por Amostra de Domicílios, que, no quarto trimestre de 2018, pesquisou o acesso dos domicílios brasileiros à Tecnologia da Informação e Comunicação (TIC). Segundo a PNAD, o percentual de domicílios que utilizavam a Internet subiu de $74,9 \%$ para $79,1 \%$, de 2017 para $2018^{16}$.

São, assim, de acordo com a pesquisa TIC Domicílios 2019, 47 milhões de não usuários, ou 26\% da população. O celular é o dispositivo mais utilizado - 99\% dos usuários da rede no Brasil (mesma ordem de grandeza na PNAD). É interessante observar que, na área rural e nas classes $D$ e $E$, o uso exclusivo do smartphone para acessar a web chega a $79 \%$ e $85 \%$, respectivamente.

Mas é na dimensão dos microdados relativos aos indivíduos ${ }^{17}$ que a pesquisa TIC Domicílios 2019 ganha ainda mais importância para este artigo. Nessa perspectiva, 59,9\% das pessoas que nunca usaram um computador são negras, mulheres (56\%) e habitam em área urbana (77\%). Entre as pessoas que nunca acessaram a internet, $53 \%$ são negras também. Destas, pouco mais da metade $(52,3 \%)$ são mulheres, e $37 \%$ são das regiões Norte e Nordeste. A população preta e parda também tem menores índices de uso diário, bem como depende mais de instituições públicas e privadas para usar a rede mundial de computadores.

\footnotetext{
${ }^{16}$ Disponivel em https://agenciadenoticias.ibge.gov.br/agencia-detalhe-de-midia.html?view=mediaibge \&catid=2103\&id=3674

${ }_{17}$ Disponíveis em https://cetic.br/pt/arquivos/domicilios/2019/individuos/
} 
A pesquisa levantou que a falta de habilidade com o computador é uma das causas pelas quais uma parcela da população em geral nunca acessou o ciberespaço. Entre pretos e pardos, essa razão atinge $54 \%$. Em termos comparativos, não saber lidar com um dispositivo computacional habilitado para navegar em rede é um problema que atinge $35,3 \%$ da população branca que nunca navegou.

Sobre o uso da internet, a maior parte das pessoas que afirma não fazer downloads, criar e compartilhar conteúdo são pretas e pardas (60,9\%). O mesmo se dá para os usuários de internet que consomem menos multimídia (jogos, música, filmes, podcasts, informação jornalística, filmes ou séries) - a maior parte são homens e mulheres pretos e pardos.

A maior ausência em atividades de educação e trabalho (pesquisas escolares, cursos a distância, busca por informações sobre cursos de graduação e pós-graduação, uso da internet para estudo por conta própria, guarda e armazenamento de dados e atividades diretamente relacionadas a trabalho) também se verifica entre pretos e pardos.

Os números indicam uma desigual participação em ambientes telemáticos por parte de populações pretas e pardas - tanto consumindo quanto produzindo narrativas, registros, interpretações da realidade, debate, entre outras formas possíveis de participação no ciberespaço. Apesar disso, ou talvez por isso mesmo, verifica-se empiricamente o protagonismo de coletivos de comunicadores e comunicadoras negros e negras, pautando questões urgentes e fundamentais - insegurança alimentar, genocídio da população negra, violência policial e a fome, entre outras - em todos os grandes centros urbanos brasileiros. Ao mesmo tempo, emerge uma geração de jovens comunicadores negros em áreas tão diversas como moda, estética, política, economia e trabalho, contribuindo, como influenciadores digitais, com elementos de representatividade negra no debate público.

O que essas experiências indicam ratifica a sugestão de Celly Brito Lima e Miriam de Albuquerque Aquino (2009), que defendem a necessidade de investigação da construção de identidades afrodescendentes na cibercultura, no contexto das condições de acesso e democratização da informação da realidade brasileira. Para as autoras, problematizar a construção de identidades é importante na medida em que é uma forma por meio da qual é possível conhecer os interesses, as necessidades e os desejos de atores sociais em condição histórica de exclusão social que produz situações aparentemente 
contraditórias: de um lado, a constatação de sérias dificuldades estruturais de acesso e, de outro, a emergência de uma presença vigorosa de identidades negras em rede.

Já Míriam Aquino (2010) observa a necessidade de construção de projetos políticos que postulem o reconhecimento da diversidade cultural e elaborem políticas de informação que se adequem à necessidade de inclusão de grupos socialmente marginalizados. É nesse sentido que os elementos de uma pedagoga popular aqui sugerida procuram fortalecer elementos culturais que observem e fortaleçam aspectos de identidades afrodescendentes. Ou seja, que considerem a diversidade cultural e ofereçam condições para afrodescendentes enfrentarem as incertezas, os imprevistos e as indeterminações oriundas do apartheid cultural também na cultura digital.

Trata-se de linhas de ação pedagógica e de filosofia de ação (AQUINO, 2010) que procuram contribuir com expertises necessárias à identificação e à auto-representação - e se contraponham às ameaças representadas pelas condições estruturais que dificultam o acesso ao ciberespaço, como demonstram os dados da pesquisa TIC Domicílios 2019.

\section{Considerações finais}

Os aprendizados e produções midiáticas a partir das experiências larossianas das populações da diáspora negra estão vinculados às características de seus corpos, enquadrados pelos racismos institucional, estrutural e cotidiano (KILOMBA, 2010), em condições hierarquicamente inferiores no tecido social. O corpo fala. Ou seja, é o corpo negro o condutor da necessidade de criação, transformação e invenção mesmo na adversidade - ou justamente por causa dela. Há um potencial pedagógico nessa perspectiva, pois ela incorpora a noção de encruzilhada, que emerge não como uma construção arquitetônica sem saída, ou como impossibilidade, mas como disponibilidade para novos rumos.

É claro que as condições históricas e estruturais com as quais as populações pretas e pardas lidam são cenários de escassez, desencantamento e monologização da vida - os dados da pesquisa TIC Domicílios 2019 expressam bem isso no terreno da cultura digital brasileira. Ao mesmo tempo, não fosse a potência transgressiva que aponta para um campo de possibilidades abertas, de poéticas, de práticas de invenção e afirmação de vidas, não veríamos as experiências em andamento que transgridem os limites da herança colonial impressas nas vidas das populações afrodescendentes brasileiras. 
Esse é o tipo de dobra (de drible?) que uma pedagogia afro-centrada propõe: uma prática em encruzilhadas que se constitui como uma invocação, filosófica e pedagógica, da ancestralidade como princípio de presença, saber e comunicações (RUFINO, 2019). Como já afirmado, a encruzilhada é o principal conceito associado às potências do Orixá Exu - ou seja, é a expressão mítica das possibilidades abertas a partir de uma perspectiva decolonial afrobrasileira, a que uma pedagogia afro-centrada para a produção de narrativas está vinculada. Com isso, procuro expressar que, se a sociedade é da informação, o recurso pedagógico ao Orixá Exu e suas potências também é fundamental para conhecer e intervir nessa sociedade (colocar-se como sujeito). Compreender que, sem o trânsito, o movimento, os fluxos, a comunicação, nada acontece, nada se transforma, nada se cria.

Não se trata, portanto, somente do acesso à internet e a dispositivos computacionais, mas sobretudo da disposição de uso - de um saber-fazer que extrapole a condição de usuário passivo das tecnologias de informação e comunicação. Refiro-me ao desenvolvimento de mecanismos (físicos, lógicos e metodológicos) para produção e usufruto de informação; de metodologias de apropriação tecnológica; de normas para o compartilhamento livre de bens simbólicos que podem ser associados, em processos de aprendizagem afro-centrada, à referência de Exu, o patrono da criação e da invenção. O desenvolvimento de tais mecanismos constitui fronts para os interesses das populações menos assistidas e, em particular, dos povos afrodescendentes.

Esses fronts indicam uma atuação sobre a cultura em termos do relacionamento com o objeto técnico e em termos de produção e usufruto de bens informacionais, em especial. O quando desse front é o cotidiano - ou seja, uma perspectiva afro-centrada para a produção de narrativas investe na criação e na invenção, mas também numa aproximação com os objetos técnicos que os desmistifique, que os coloque na ordem do dia a dia, como ingredientes da vida rotineira, do mesmo jeito que são encarados todos os Orixás, forças vivas da criação, que habitam o cotidiano na tradição religiosa de matriz africana nagô.

Há um forte investimento necessário à agenda de uma pedagogia afro-centrada para a produção de narrativas com mídias em sociedades hipermediadas. Recorro agora às potências míticas de Oxum para tratar, em parte, desse aspecto. A deusa sugere o recurso ao autoconhecimento como tecnologia ancestral para se proteger e agir sobre os movimentos em seu entorno, sobre a realidade. 0 uso do espelho ${ }^{18}$ indica

\footnotetext{
${ }^{18}$ Mas também dos instrumentos de divinação no sistema Ifá. Oxum é a única Orixá a dominar os segredos do oráculo.
} 


\section{ALCEU}

ISSN: $2175-7402$

essa capacidade de lançar mão dos dispositivos técnicos em seu benefício, de tecnologias de cuidado, que precisam ser manuseadas tanto por homens quanto por mulheres para o bom equilíbrio do espaço comum. Esse apelo ao autoconhecimento corresponde à atenção à condição psicológica construída pelas condições externas ao indivíduo, e, por meio dela, é possível tematizar, pedagogicamente, a dimensão da ancestralidade, da identidade e da negritude como marcadores de protagonismo narrativo com mídias.

A maternidade pertinente a Oxum tem sido suprimida do caráter Yalodê, ou seja, a matriz que representa a matripotência daquela que ama seu povo e que vai ao espaço público denunciar as injustiças. São muitos os desequilíbrios presentes no ecossistema midiático, como vimos. A ausência de mulheres no uso de computadores e no acesso à internet, exposta nos dados analisados, é uma face desses desequilíbrios. O que vimos no mito de Oxum é que ele coloca em xeque a naturalidade dos papéis de gênero e problematiza a prepotência masculina - um fator a ser considerado seriamente nos processos de educação midiática e produção de narrativas centradas em meninas, jovens e mulheres. Mas também a ser observado em processos educacionais que envolvam o uso de programação, design, manipulação e configuração de dispositivos computacionais - elementos tradicionalmente associados exclusivamente ao protagonismo masculino.

A problematização se estende ainda à qualificação da mulher negra e a seu lugar no mundo - ou seja, às narrativas sobre ela. O resgate do protagonismo feminino com tecnologias, e com as narrativas produzidas com essas tecnologias, se projeta também para produzir mídias que superem as cosmovisões etnocêntricas nas quais Oxum, mas também as mulheres negras, são enquadradas como sereias de águas doces, deusas vênus, sedutoras narcisistas, o que não corresponde, necessariamente, às formas pelas quais elas querem ser vistas e consideradas.

Finalizo estes comentários finais tratando de alguns aspectos do personagem melanodérmico Ogum, como intercessor de processos de aprendizagem com tecnologias para a produção de narrativas. Como relata Reginaldo Prandi (2019, p. 13), Ogum é antes de tudo um herói civilizador. Ele personifica os diferentes momentos da própria evolução da humanidade, que recebeu dele a cultura material, que garantiu seu alastramento na Terra. Na longa marcha da história, Ogum foi coletor, caçador, senhor das matas, grande provedor, ferreiro, a partir de sua potência é que se instauram as indústrias, se inventam novas profissões, meios de produção, que se muda das matas e se inventam as cidades. 
Esta é a sina de Ogum: acompanhar a humanidade e morar nos caminhos do mundo, apesar de ser rei; banhar-se de sangue, apesar de ter água em casa; usar palhas secas para se proteger do frio; vencer guerras, mas dispensar os espólios do conflito ${ }^{19}$. Ogum é o orixá das contradições e das ambiguidades. $\mathrm{O}$ mesmo ferro que prepara a terra para o alimento e a vida também faz a espada que ameaça a vida; a mesma tecnologia que abre possibilidades emancipatórias pode servir para impedir que elas aconteçam.

As capacidades articulatórias das tecnologias de informação e comunicação possuem, na mesma medida, uma capacidade de isolamento de seus usuários. O personagem nos ensina que a articulação coletiva, a integração comunitária, a valorização do comum, são fatores que realçam positivamente as potências dos aprendizados com tecnologias para a produção de narrativas.

O presente trabalho procurou explorar alguns recursos fornecidos pelo panteão do Candomblé de matriz Nagô como meios para intensificar processos de aprendizagem com tecnologias digitais necessárias para a produção e circulação de narrativas que emergem das populações afrodescendentes no Brasil.

As características de alguns dos Orixás mencionados podem atender a estratégias de aprendizado que se coloquem como respostas a problemas e desafios que se apresentam para as populações pretas e não brancas. É o caso de acionar as potências de Exu como personagem que incide sobre processos criativos e disruptivos, e sua capacidade de ressignificação.

No mesmo sentido, sugeriu-se a necessidade de autoconhecimento (fornecido por um Odu de Oxum) como elemento necessário para a intervenção (narrativa) na realidade. E a observação da necessidade do contato com os semelhantes no âmbito das tecnologias - sinalizada pelos problemas advindos do isolamento e do ensimesmamento tematizado por meio das narrativas do Orixá Ogum.

São inúmeras as associações desse tipo que são passíveis de serem realizadas. O modelo esboçado aqui, como já afirmado, é resultado de uma pesquisa ainda em andamento e que será levado a campo, nos próximos meses, para que sejam avaliadas, em terreiros de Candomblé na cidade do Recife, a viabilidade dessas possibilidades e sua efetividade.

\footnotetext{
${ }^{19}$ Características retiradas de diferentes Odus de Ifá
} 
Luiz Carlos Pinto da Costa Júnior

ORCID: https://orcid.org/0000-0002-4112-4152

Universidade Católica de Pernambuco, Departamento de Jornalismo, Recife (PE), Brasil. Doutor em Sociologia / UFPE

E-mail: lula.pinto@unicap.br

Recebido em: 1 de maio de 2020.

Aprovado em: 8 de agosto de 2020.

\section{Referências:}

AGAMBEN, Giorgio. O que é o contemporâneo? e outros ensaios. Chapecó: Editora Argos, 2009.

AQUINO, Mirian de Albuquerque. Políticas de informação para inclusão de negros afrodescendentes a partir de uma nova compreensão da diversidade cultural. Inclusão Social, Brasília, v. 3, n. 2, p. 25-35, 2010

. A inclusão étnico-racial na era da informação. Revista Digital de Biblioteconomia e Ciência da Informação, v.11, n.2, p. 61-75, 2013.

ASANTE, Molefi Kete. Afrocentralidade: notas sobre uma posição disciplinar, In.: NASCIMENTO, Elisa Larkin (Org.). Afrocentricidade - Uma abordagem epistemológica inovadora. São Paulo: Selo Negro (2009).

CARNEIRO, Sueli. Escritos de uma vida. São Paulo: Pólen Livros, 2019.

CERTEAU, Michel. A invenção do cotidiano: Artes de fazer. Petrópolis: Vozes, 1994.

CESARINO, Letícia. Estudos pós-coloniais da ciência e tecnologia: desafios e possibilidades. Anais V Reunião de Antropologia da Ciência e da Tecnologia (2015).

CETIC.BR. TIC Domicílios 2018. Disponível em: https://www.cetic.br/tics/domicilios/2018/domicilios/A4/. Acesso em: 01 set.2020

CGI.br, Comitê Gestor da Internet no Brasil. Pesquisa TIC Domicílios 2019. Disponível em: <https://cetic.br/media/analises/tic_domicilios_2019_coletiva_imprensa.pdf>. Acesso em: 01 set. 2020.

COGO, Denise.; MACHADO, Sátira. Redes de negritude: usos das tecnologias e cidadania comunicativa de afro-brasileiros. In.: XXXIII Congresso Brasileiro de Ciências da Comunicação. Anais Eletrônicos... São Paulo: $\quad 2010 . \quad$ Intercom, Disponível em: <https://www.intercom.org.br/papers/nacionais/2010/trabalhos.htm>. Acesso em: 08 de Setembro de 2020. 
COLLINS, Patricia Hill. Black Feminist Thought, Knowledge, Consciousness and the politics of Empowerment. New York: Routledge, 2000.

COULDRY, Nick; MEJIAS, Ulises A.. 2019. Data Colonialism: Rethinking Big Data's Relation to the Contemporary Subject. Television \& New Media 20 (4): 336-49.

DELEUZE, Gilles; GUATTARI, Félix. O que é a filosofia? São Paulo: Editora 34, 1992.

. Diferença e repetição. 2. ed. Rio de Janeiro: Graal, 2006.

. Proust e os signos. 2. ed. Rio de Janeiro: Forense Universitária, 2003.

DELORY-MOMBERGER, Christine. A pesquisa biográfica ou a construção compartilhada de um saber do singular. Revista Brasileira de Pesquisa (Auto) Biográfica, Salvador, v. 01, n. 01, p. 133-147, jan./abr. 2016

DA COSTA JÚNIOR, Luiz Carlos Pinto; FALTAY, P. . Políticas e poéticas dos rastros. REVISTA ECO-Pós (ONLINE), v. 18, p. 77-94, 2015.

. Um estudo de uma pedagogia da dubversão do objeto técnico. In.: IX Simpósio Nacional da ABCiber. Anais eletrônicos... São Paulo: ABCiber, 2017. Disponível em: <//abciber2016.com/anaiseletronicos/>. Acesso em: 08 de Setembro de 2020.

DIOP, Cheikh Anta. Antériorité des civilisations nègres : mythe ou vérité historique? Paris: Présence africaine, 1967.

GALLO, Silvio. As múltiplas dimensões do aprender... In: Congresso de Educação Básica - COEB: aprendizagem e currículo. Anais do... Florianópolis: COEB, 2012. Disponível em: <http://www.pmf.sc.gov.br/arquivos/arquivos/pdf/13 02 2012 10.54.50.a0ac3b8a140676ef8ae0dbf32e6 $\begin{array}{lllll}\text { 62762.pdf>. } & \text { Acesso } & \text { em: } & 15 & \text { Abril. }\end{array}$ . Teoria em ato: o que pode e o que aprende um corpo? Revista Educação e Pesquisa, v. 41, n. especial, p. 1541-1552, dez., 2015.

GLISSANT, Edouard. Poética da Relação. Porto: Porto Editora, 2011

KILOMBA, Grada. Memórias da plantação. Episódios de racismo cotidiano. São Paulo: Editora Cobogó, 2019.

LAROSSA, Jorge. Tremores - Escritos sobre experiência. Belo Horizonte: Autêntica Editora, 2014.

LIMA, C. B.; AQUINO, M. DE A. A construção de identidades afrodescentes na cibercultura: o olhar da Ciência da Informação. Informação \& Sociedade: Estudos, v. 19, n. 1, 28 mar. 2009.

LÓPEZ, Maximiliano Valério. Acontecimento e experiência no trabalho filosófico com crianças. Belo Horizonte: Autêntica Editora, 2018.

NASCIMENTO, Abdias. O Quilombismo, São Paulo: Editora Perspectiva, 2019. 
NASCIMENTO, Wanderson Flor. Corpo: objeto de um discurso. Seminário Internacional Michel Foucault: Perspectivas. Simpósio Temático no 6: Relações de Gênero: Corpo, Poder e Subjetividades, p. 748-754, 2004.

. Ensino de filosofia e filosofia africana: dimensões metafilosóficas na discussão curricular. NESEF. Curitiba, v. 6, n. 6, p. 17-25, jun.-dez. 2015.

MORAES, Alana; TARIN, Bruno; TIBLE, Jean. (Orgs.). Cartografias da emergência. São Paulo: Friedrich Ebert Stiftung (2015).

NOGUEIRA, Renato. Denegrindo a filosofia: o pensmento como coreografia de conceitos afroperspectivistas. Griot - Revista de Filosofia, v.4, n.2, p. 1-19, dez. 2011.

Mulheres e deusas - como as divindades e os mitos femininos formaram a mulher atual. Rio de Janeiro: Harper Collins, 2017).

MESQUITA, Rui Gomes de Mattos. Ao redor do Baobá: anotações sobre a memória e currículo na roteirização de uma imagem (in)vizibilizada. REU, v. 39, n. 2, p. 393-407, dez. 2013.

; RAMALLO, F. . La mandinga y los ambientes narrativos entre la mediación pedagógica y la descolonización de la educación. Revista de Educación. N 14, p. 121-135, 2018.

; TAVARES, Mauricio Antunes. Nós para atar e desatar: relações entre educação e cultura. Recife:

Ed. UFPE, 2019.

PRANDI, Reginaldo. Mitologia dos Orixás. São Paulo: Companhia das Letras, 2001.

RANCIÉRE, Jacques. O desentendimento - política e filosofia. São Paulo: Editora 34, 1996.

RUFINO, Luiz. Pedagogia das Encruzilhadas. Rio de Janeiro: MV Serviços e Editora, 2019.

SANTOS, Juana Elbein dos. Os nàgô e a morte: pàde, asèsè e o culto Ègun na Bahia. Petrópolis: Vozes, 2002.

SANTOS, Boaventura de Souza. Renovar a teoria crítica e reinventar a emancipação social. São Paulo: Boi Tempo, 2007.

SIMONDON, Gilbert. A individuação à luz das noções de forma e de informação. São Paulo: Editora 34, 2020.

SORJ, B., and GUEDES, LE. Internet na f@vela: quantos, quem, onde, para quê [online]. Rio de Janeiro: Centro Edelstein de Pesquisa Social, 2008. Introdução. pp. 4-22. ISBN 978-85-99662-46-5. Available from SciELO Books <http://books.scielo.org>.

TEIXEIRA, Carla Patrícia; PINTO, Luiz Carlos. Uma análise afro-orientada do game "Contos de Ifá". Revista Cadernos da Escola de Comunicação - vol. 17, no. 1, Jan / Dez 2019. 
WAISELFISZ, Julio Jacobo. Mapa das desigualdades digitais no Brasil. Brasília: RITLA; Instituto Sangari; Ministério da Educação, 2007.

WENGER, Etienne y Beverly. Comunidades de práctica: una breve introducción. Disponível en http://www.pent.org.ar/institucional/publicaciones/comunidades-practica-una-breve-introduccion, mar 2021.

\section{Resumo}

$\mathrm{O}$ artigo reflete o atual estágio de uma pesquisa em andamento. $\mathrm{O}$ texto procura, a partir do repertório da filosofia afroperspectivista, indicar elementos de uma pedagogia popular do uso de tecnologias da informação e comunicação para a produção de narrativas. Esse esforço, de ordem conceitual e metodológico, evoca signos e personagens das histórias e culturas afro-brasileiras e africanas, em particular do Candomblé Nagô praticado no Brasil. O recurso a uma matriz simbólica afro-brasileira também se presta à desmistificação das tecnologias, na medida em que o uso de computadores, redes e outros dispositivos pode ser associado à mesma vivência cotidiana dedicada ao culto de Orixás.

Palavras-chave: Afroperspectiva, Pedagogia, Tecnologia, Narrativas, Candomblé.

\section{Abstract}

The article reflects the current stage of an ongoing research. The text seeks, based on the repertoire of Afroperspectivist philosophy, to indicate elements of a popular pedagogy of the use of information and communication technologies for the production of narratives. This effort, conceptual and methodological, evokes signs and characters from Afro-Brazilian and African histories and cultures, in particular Candomblé Nagô practiced in Brazil. The use of an Afro-Brazilian symbolic matrix is also useful to the demystification of technologies, since the use of computers, networks and other devices can be associated with the same daily experience dedicated to the worship of Orixás.

Keywords: Afroperspective, Pedagogy, Technology, Narratives, Candomblé. 


\section{Resumen}

El artículo refleja la etapa actual de una investigación en curso. El texto busca, desde el repertorio de filosofía afroperspectivista, indicar elementos de una pedagogía popular del uso de las tecnologías de la información y la comunicación para la producción de narrativas. Este esfuerzo, conceptual y metodológico, evoca signos y personajes de las historias y culturas afrobrasileñas y africanas, en particular el Candomblé Nagô practicado en Brasil. El uso de una matriz simbólica afrobrasileña también se presta a la desmitificación de tecnologías, en la medida en que el uso de computadoras, redes y otros dispositivos puede asociarse con la misma experiencia diaria dedicada al culto de Orixás.

Palabras clave: Afroperspectiva, Pedagogía, Tecnología, Narrativas, Candomblé.

Este artigo é publicado em acesso aberto (Open Access) sob a licença Creative Commons Attribution Non-Commercial (CC-BY-NC 4.0), que permite que outros remixem, adaptem e criem a partir do seu trabalho para fins não comerciais, e embora os novos trabalhos tenham de lhe atribuir o devido crédito e não possam ser usados para fins comerciais, os usuários não têm de licenciar esses trabalhos derivados sob os mesmos termos. 